\title{
Effectiveness of the Epleys Maneuver for Treatment of Benign Paroxysmal Positional Vertigo
}

\author{
Salah Uddin Ahmmed', Md Zakir Hossain ${ }^{2}$, Mohammad Neser Uddin², Sarder Mohammad Golam \\ Rabbani $^{2}$, Arba Md Shaon Mursalin Alman³.
}

Abstract

Background: Benign Paroxysmal Positional Vertigo (BPPV) is one of the most frequent vestibular disorder. It is characterized by recurrent spells of vertigo associated with certain head movements such as turning the head to right or left, getting out of bed, looking up and bending down.

Objectives: The aim of this study was to compare the efficacy of treatment by the Epley maneuver with medicine and medicine (betahistine) only for benign paroxysmal positional vertigo.

Materials and Methods: Fifty six patients with benign paroxysmal positional vertigo were randomly divided in two groups. One group was treated with Epley maneuver wth medicine as case and other group with only medicine (betahistine) as control.

Results: At the end of first week who were treated with Epley maneuver with medicine, 24 (85.71\%) patients recovered and $27(96.42 \%)$ were recovered at second week and all the $28(100 \%)$ were found recovered at end of third week. Whereas, who treated with betahistine only $7(25.00 \%)$ recovered at end of first week $22(78.58 \%)$ recovered at second week, 25 (89.29\%) recovered at third week and all the 28 $(100 \%)$ were at end of fourth week. Who received only medical therapy needed one more extra visit than case patients

Conclusion: Treatment of BPPV with the Epleys manouvre with medicine resulted in early better and improvement of symptoms than with medicine alone.

Keywords: Benign paroxysmal positional vertigo, Epleys manouvre, betahistine.

1.Classified ENT specialist,Combined Military Hospital, Rangpur.

2.Classified ENTspecialist,Combined Military Hospital,Dhaka.

3.Medical officer,Combined Millitary Hospital,Rangpur.

Address of Correspondence:Dr.Lt Col Salah Uddin Ahmmed,Classified ENT specialist,Combined Military Hospital,Rangpur.

Email:suahmmed@yahoo.com

\section{Introduction}

Benign Paroxysmal Positional Vertigo (BPPV) is a common clinical disorder characterized by brief recurrent spells of vertigo often brought about by certain head position changes as may occur with looking up, turning over in bed, or straightening up after bending over ${ }^{1}$. It is considered as one of the most frequent disorder of the vestibular system and an important cause of vertigo with a prevalence of 11 to 64 per 100000 patients a year and a lifetime prevalence of 2.4 percent ${ }^{1,2}$. It is benign because it is not progressive; paroxysmal because it is sudden and unpredictable in onset; positional because it comes about because of a change in head position and vertigo because of a sense of spinning of the room or whirling ${ }^{3}$. The condition most often occurs spontaneously and is 
prevalent in the elderly patients; age range between 50 and 55 years and is rare in childhood 4, 5 .Females are more frequently affected than male, with a female to male ratio of 2-3: $1^{6}$. Patients with BPPV are 5 times more likely to have relatives with BPPV compared to other dizzy patients suggesting a familial tendency ${ }^{7}$. BPPV is found primary or idiopathic in approximately $50 \%$ to $70 \%$ of all cases. Reported recurrence rate of BPPV is $20 \%$ to $30 \%$, but it may be as much as $50 \%$ of recurrence. Age, sex, presence of residual instability after the repositioning maneuvers, complexity of primary treatment and cause have been related to the development of recurrences ${ }^{8}$. It is more frequently seen at older ages probably due to the degeneration of statoconia, arising from demineralization, shown by means of histopathology studies and hormonal dysfunction. It may also result from cranial trauma, vertebrobasilar insufficiency, otological surgery, endolymphatic hydrops, vestibular neuritis or middle ear diseases. An association between BPPV and meniere's disease has been reported 9,10 .

In addition to rotatory dizziness, this causes positional nausea, vomiting, sudoresis, disequilibrium and sometimes tinnitus 11. Subtypes of BPPV are distinguished by the particular semicircular canal involved and whether the detached otoconia are free floating within the affected canal (canalolithiasis) or attached to the cupula (cupulolithiasis). BPPV is typically unilateral, although in some cases it may be bilateral ${ }^{8}$. Clinical history and eyefindings during positional testing are the gold standards. This finding is elicited by performing specific maneuvers, depending on which canal is affected. Dix-Hallpike manoeuvre can be confirmed ${ }^{12,10}$. Different other diagnostic maneuvers such as; supine head roll test, head pitch test, head down test, horizontal roll test may also help to confirm the diagnosis ${ }^{13}$. Electronystagmography, imaging with CT scanning or MRI may be necessary where atypical or unusual features are present 10. BPPV is usually a self-remitting disorder and may resolve as time goes on without specific treatment ${ }^{5}$. Treatment for BPPV is by returning or "repositioning" the detached otoconia back to the utricle. The commonly used techniques are the Epley canalith repositioning procedure and the Semont liberatory maneuver ${ }^{14}$. Successful treatment depends mainly on the choice of the most appropriate maneuver for the case. In some patients vestibular suppressant medications are recommended as adjuncts not only to relieve the vertigo after maneuver but also to control the clinical symptoms until the procedure can be repeated ${ }^{15}$.

\section{Methods}

The study was conducted in the Department of ENT, CMH, BAF for a period of two years from June 2015 to July 2017. A total of 56 BPPV patients above 18 years of age were included in the study. The diagnosis of BPPV was based on the clinical history and positive Dix Hallpike maneuver. Patients reacting positively to Dix Hallpike maneuver were included in the study. Informed written consent was taken from all of the patients. The patients with cervical spondylosis, ongoing CNS disease (stroke or TIA), known cardiovascular disease, migraine, severe eye disorders, unable to ambulate and pregnant women were excluded from this study 16, 17. 56 study participants with positive positional test were divided into two groups each consisting of 28 patients. One group of 28 patients who received medical therapy with Epley's maneuver were considered as cases and the other group of 28 patients who received only medical therapy (betahistine) were considered as controls. Epley's maneuver will be repeated until symptomatic relief. The results were classified after treatment with and without the Epley maneuver into resolution of vertigo, presence of nonpositional vertigo, partial resolution and same or worse. We followed the patients for one month with review visit at the 1st week, $2^{\text {nd }}$ week, 3rd week and at the end of $4^{\text {th }}$ week. The follow up process was explained to the patients. Preprocedural and postprocedural instructions were given to all the patients who undergo Epley maneuver. The study protocol was approved by Institute Ethical Committee. 


\section{Result}

In the present study it was observed that there was predominance of female gender. We found 34 female (60.71\%) and $22(39.29 \%)$ male patients and the ratio was $1.54: 1$. In group - A, out of 28 patients $35.71 \%$ was male and 64.29 $\%$ were female. In group - B, $71.42 \%$ were female and $28.58 \%$ were male. Among the 56 patients BPPV was found more prevalent in the elder age, we found it is predominated in the 41 to 60 year age group.

Table-I: Gender profile.

\begin{tabular}{|l|l|l|}
\hline Gender & $\begin{array}{l}\text { G1 = Case } \\
(\%)\end{array}$ & $\begin{array}{l}\text { G2 = Control } \\
(\%)\end{array}$ \\
\hline Male & $12(42.86 \%)$ & $11(39.29 \%)$ \\
\hline Female & $16(57.14 \%)$ & $17(60.71 \%)$ \\
\hline Total & $28(100 \%)$ & $28(100 \%)$ \\
\hline
\end{tabular}

Table-II: Age distribution of the patients

\begin{tabular}{|l|l|l|}
\hline Age & Case $(n=28)$ & Control $(n=28)$ \\
\hline$<40$ & $2(7.14 \%)$ & $2(7.14 \%)$ \\
\hline $41-50$ & $5(17.86)$ & $6(21.42 \%)$ \\
\hline $51-60$ & $15(\%)$ & $17(60.71 \%)$ \\
\hline$>60$ & $6(21.42 \%)$ & $3(10.71 \%)$ \\
\hline
\end{tabular}

Among the 28 case patients, 24 (85.71\%) patients found recovered from vertigo at first week of follow-up, 27 (96\%.42\%) were recovered at second week of follow-up and all the $28(100 \%)$ case patients were found recovered from vertigo at end of third week follow-up visit. Whereas, among 28 control patients $7(25.00 \%)$ recovered from vertigo at first follow-up, $22(78.58 \%)$ recovered at second week visit, $25(89.29 \%)$ recovered at third week visit and all the $28(100 \%)$ were found recovered from vertigo at end of fourth week follow-up visit.
It is noted that $3(10.71 \%)$ control patients, who received only medical therapy needed one more extra visit than case patients (Table-III).

Table-III: Comparison of response between Epley's maneuver and controls among BPPV patients

\begin{tabular}{|l|l|l|l|l|}
\hline & $\begin{array}{l}\text { 1s } \\
\text { week }\end{array}$ & $\begin{array}{l}\text { 2nd } \\
\text { week }\end{array}$ & $\begin{array}{l}\text { 3rd } \\
\text { week }\end{array}$ & $\begin{array}{l}\text { 4th } \\
\text { week }\end{array}$ \\
\hline $\begin{array}{l}\text { Medical with } \\
\text { therapy with } \\
\text { Epley's } \\
\text { maneuver } \\
\text { (Case) }\end{array}$ & 24 & 3 & 1 & 0 \\
\hline $\begin{array}{l}\text { Only medical } \\
\text { therapy } \\
\text { (Control) }\end{array}$ & 7 & 15 & 3 & 3 \\
\hline
\end{tabular}

\section{Discussion}

There were 33 female and 23 male in this study. The number of female was 1.54 fold more than male. In the several studies, done by Brevem M et al. and Yetiser $S$ found female predominance which correlates with our study ${ }^{18,19}$. In another study by Ogun OA et al. found female more than male with $2.6: 1$ female to male ratio ${ }^{18}$.

BPPV is more prevalent in the elderly and in the present study; we found it is more common in the 41 - 60 year age group. Almost similar finding was found in the study done by Caldas et al. in 2009 from Brazil. It was also supported that BPPV is common in older age group by several other studies ${ }^{20,21 .}$

In the present study, we found that up to 24 $(85.71 \%)$ of patients got benefit after the first follow-up visit of one week. In a study from Turkey, they found $86.2 \%$ of patients were improved after a single session with Epley maneuver ${ }^{22}$. In a study done by Parfenov VA et al. found clinical response in $75.7 \%$ of patients at second Visit and $94.4 \%$ of patients at end of medicinal treatment by betahistine ${ }^{23}$. In another study done by Mantello EB et al. cocluded that the treatment of BPPV based on repositioning 
maneuvers is highly effective ${ }^{11}$. In another study done by Gaur $S$ et al. found Epley's maneuver was more effective than medicines alone not only in treating the condition but also in preventing the recurrence. Majority of the case patients recovered during their first visit and those who were treated with medicines alone needed more number of visits. Epley maneuver was more effective in the treatment of BPPV against the medical therapy ${ }^{17}$. A comparative study done by Kaur J and Shamanna $\mathrm{K}$ found that Epleys with Betahistine group showed higher percentage of improvement $(94.8 \%)$ as compared to the Betahistine alone group $(87.1 \%)$. Not only higher rate of percentage, patients this group also showed earlier resolution within first 2 days of treatment, longer relief of symptoms and no relapse or recurrence. They also found that the Epleys with Betahistine group 1 patient did not improve at the end of 1 week. On the other hand patients in the Betahistine alone group showed improvement of symptoms 4 - 5 days after the starting of treatment. In this group, 2 patients did not respond to treatment at the end of 1 week and 1 patient did respond at 4 weeks and was termed as non-responder. 1 patient had recurrence of symptoms at 4 weeks after initial improvement and was termed as relapse ${ }^{16}$.

\section{Conclusion}

Benign Paroxysmal Positional Vertigo is a common syndrome in ENT clinical practice. Its prognosis is usually good but can recur. There are various vestibular rehabilitation exercises and medical treatment are available for the treatment of BPPV. Patients should be reassured about the benign nature of the condition and the possible treatment options. Amongst the different treatment options, it can be said that treatment with Epleys manouevre appeared to be an effective and safe option for reducing vertigo-associated symptoms.

\section{References}

1. Xiang-Dong G. Benign paroxysmal positional vertigo. Journal of Neurosciences in Rural Practice 2011; 2(1): 109-110.

2. Andre APR, Julio Cesar Moriguti JC and Moreno NS. Conduct after Epley's maneuver in elderly with posterior canal BPPV in the posterior canal. Brazilian Journal of Otorhinolaryngology 2010; 76 (3): 300-3005.

3. Aydin E, Akman K, Yerli H and Ozluoglu LN. Benign paroxysmal positional vertigo after radiologic scanning: a case series. Journal of Medical Case Reports 2008; 2: 92.

4. Gananca FF, Simas R, Gananca MM, Korn GP and Dorigueto RS. Is it important to restrict head movement after Epley maneuver? Brazilian Journal of Otolaryngology 2005; 71 (6):764 - 768.

5. Alvarenga GA, Barbosa MA and Porto CC. Benign Paroxysmal Positional Vertigo without nystagmus: diagnosis and treatment. Brazilian Journal of Otorhinolaryngology 2011; 77 (6): 799 - 804.

6. Lee $\mathrm{S}$ and Kim JS. Benign Paroxysmal Positional Vertigo. J Clin Neurol. 2010; 6 (2): 51-63.

7. Parham K. Benign Paroxysmal Positional Vertigo: An Integrated Perspective. Advances in Otolaryngology 2014; 2014: 1-17. doi:10.1155/2014/792635.

8. Sonu P, Sujjata S, Jagriti B and Rekha C. Benign paroxysmal positional vertigo: Pathophysiology, Causes, Canal Variants and Treatment. International Journal of Advanced Research 2015; 3 (7): 54-60.

9. Korn GP, Dorigueto RS, Gananca MM and Caovilla HH. Repeated Epleys maneuver in the same session in benign positional paroxysmal vertigo. Brazilian Journal of Otolaryngology 2007; 73 (4): 533 - 539.

10. Pames LS, Agarwal SK, and Atlas J. Diagnosis and management of benign 
paroxysmal positional vertigo (BPPV). Canadian Medical Association Journal 2003; 169 (7): 681693.

11. Mantello EB, Andre APR, Moreno NS, Hyppolito MA and Moriguti JC. Long-Term Efficacy of Repositioning Maneuvers in Benign Paroxysmal Positional Vertigo. International Journal of Clinical Medicine 2011; 2: 171-177.

12. Cranfield S, Mackenzie I and Gabbay M. Can GPs diagnose benign paroxysmal positional vertigo and does the Epley manoeuvre work in primary care? British Journal of General Practice 2010; 60 (578): 698-699.

13. Bashir $\mathrm{K}$, Irfan $\mathrm{F}$ and Cameron PA. Management of benign paroxysmal positional vertigo (BPPV) in the emergency department. Journal of Emergency Medicine, Trauma and Acute Care 2014: 3. Available from: http://dx.doi.org/10.5339/jemtac.2014.3

14. Balatsouras DG, Koukoutsis G, Ganelis P, Korres GS and Kaberos A. Diagnosis of Singleor Multiple-Canal Benign Paroxysmal Positional Vertigo according to the Type of Nystagmus. International Journal of Otolaryngology 2011; 2011: 1-13.

15. Bittar RSM, Mezzalira R, Furtado PL, Venosa AR, Sampaio ALL and Oliveira CACP. Benign paroxysmal positional vertigo: diagnosis and treatment. International Tinnitus Journal. 2011; 16 (2):135-145.

16. Kaur $\mathrm{J}$ and Shamanna K. Management of Benign Paroxysmal Positional Vertigo: A Comparative Study between Epleys Manouvre and Betahistine. The International Tinnitus Journal 2017; 21 (1): 30-34.

17. Gaur S, Awasthi SK, Bhadouriya SKS, Saxena R, Pathak VK and Bisht M. Efficacy of Epley's Maneuver in Treating BPPV Patients: A Prospective Observational Study. International Journal of Otolaryngology Volume 2015; Article ID 487160, 5 pages. Available from: http://dx.doi.org/10.1155/2015/487160.
18. Brevem M, Radtke A, Lezius F, Feldmann $M$, Ziese $T$, Lempert $T$, and Neuhauser $H$. Epidemiology of benign paroxysmal positional vertigo: a population based study. Journal of Neurology, Neurosurgery, and Psychiatry 2007l; 78 (7): 710-715.

18. Yetiser $S$ and Ince D. Demographic Analysis of Benign Paroxysmal Positional Vertigo as a Common Public Health Problem. Annals of Medical and Health Sciences Research 2015; 5 (1): 50-53.

19. Ogun OA, Kristen L. Janky KL, Cohn ES, Buki B and Lundberg YW. Gender-Based Comorbidity in Benign Paroxysmal Positional Vertigo. PLoS ONE 9(9): e105546.doi:10.1371/journal.pone.0105546.

20. Bromwich $M$, Hughes $B$, Raymond $M$, Sukerman $S$ and Parnes L. Efficacy of a New Home Treatment Device for Benign Paroxysmal Positional Vertigo. Arch Otolaryngol Head Neck Surg. 2010; 13 (7): 682 - 685.

21. Guneri EA and Kustan O. The Effects of Betahistine in Addition to Epley Maneuver in Posterior Canal Benign Paroxysmal Positional Vertigo. Otolaryngology-Head and Neck Surg 2011; 146 (1): 104-108.

22. Parfenov VA, Golyk VA, Matsnev El, Morozova SV, Melnikov OA, Antonenko LM et al. Effectiveness of betahistine (48 mg/day) in patients with vestibular vertigo during routine practice: The VIRTUOSO study. PLos One 2017; 12(3): e0174114. doi: 10.1371/journal.pone.0174114. 